\title{
Development of a Web-based Decision Support System for Pediatric Patients
}

\author{
Ercüment Güvenç \\ Dep't of Information Systems \\ Engineering, \\ Muğla Sıtkı Koçman University
}

\author{
Osman Özkaraca \\ Dep't of Information Systems \\ Engineering, \\ Muğla Sıtkı Koçman University
}

\author{
Gürcan Çetin \\ Dep't of Information Systems \\ Engineering, \\ Muğla Sıtkı Koçman University
}

\author{
Gürbüz Akçay \\ Faculty of Medicine, Dep't of Pediatrics, \\ Muğla Sıtkı Koçman \\ University
}

\begin{abstract}
Information systems recently have begun to be used in the fields of health as well as in many areas, and this has led to many facilities. These systems which are used for providing guidance to physicians at their works and supporting decisions to health professionals are increasing day by day. In this study, we realized a Clinical Decision Support System intended for health professionals operating in pediatrics. Our study was carried out in three stages basically. We collected all information to medical diagnosis firstly. Then, we created a database with this information and developed a software called as Web-based Pediatric Decision Support System (Web-based PDSS) with attending physicians at the last stage. This application, enhanced with multi-layered architecture, was tested in emergency and pediatric services, and its efficacy was proven in practice. Especially, when pediatric patients come to an emergency service, and most importantly a pediatrician is not available, it was observed that Web-based PDSS decreased the diagnosis time and increased patient safety.
\end{abstract}

\section{Keywords}

Decision making, Pediatrics, Web-based systems

\section{INTRODUCTION}

Information technologies are growing every day. Moreover, these systems have begun to be used in the fields of health as in many areas, and they have provided a lot of convenience. Nowadays, physicians need to decision support systems to choose an appropriate one among the options and to cope with management of information because of the rise in the amount of medical information, the excess in the number of patients, the lack of the qualified personnel and the stresses of the workload. For this purpose, Clinical Decision Support Systems (CDSS) which are capable of guiding and assisting about clinical issues are increasing day after day.

The studies involving the use of Decision Support Systems in the health field began to appear in articles in the 1950s firstly. Then, the systems aimed at recognizing of diseases began to importance, and CDSSs became evident. CDSSs are briefly defined as a computer software supporting for decision making of health-care workers about clinical issues [1]. CDSS and expert systems, emerged in the 1960s and successfully used, have become one of the most important assistants of the health professionals. In the late of the $1960 \mathrm{~s}$, by using the Bayesian probability theory, De Bombal et al. improved a computer-based decision support system investigating the symptoms associated with abdominal disease processes [2]. In this developed CDSS, the overall accuracy percentage of the abdominal pain module was $91.8 \%$. Moreover, starting with the name of Internist project and finished with the name of CADUCEUS CDSS came out in the 1970s. It was a system that realized the diagnosis of certain diseases related to internal medicine easily and quickly [3]. Besides of these studies, in the early 1970s, MYCIN program was enhanced by the researchers of Stanford University to diagnose specific blood infections and to identify treatment methods. It has become the foundation of many expert systems development techniques currently used. As in this study, all data getting with expert cooperation builds the set of rules in MYCIN with regard to infectious diseases [4]. In addition to all these works, Poems system also was evolved for the lessexperienced medical staff in 1992. It was an urgent care medical expert system developed for post-operative care [1].

It is seen that the diversity of studies is also increasing in parallel to emerging technologies when the literature was reviewed. Works have been moved to the internet the result of growing internet technologies, and so the interaction has increased. As an example, Andreas Witch et al. developed an internet-based application in their studies. It focused on the comorbidity was identifying the problem in the serious infections and enlarged life-threading complications in the high-risk hematology-oncology patients [5].

Özel and colleagues also conducted an Intensive Care Decision Support Website, and it was evaluated with qualitative and quantitative research methods. As a result, it was seen that, website improved the accuracy of decisions $(\mathrm{p}<.001)$ but did not cause a change $(\mathrm{p}=.138)$ in the decisionmaking process [6].

In another work, CDSS was combined with health applications performed with telecommunication technologies, which have become the focus of considerable attention recently. The collected tele-health data were analyzed in an enterprise application server system while the tendencies of parameter values were been determining with statistical analysis tools and rules' substructure. A comprehensive work process engine was used for coordinating the outputs of workflow and managing the database of a core decision support system [7]. It is seen that such applications are more abundant in the literature from past to present day. Dxplain, Isabel, OIRS, Dr.CAD and HELP are good instances of CDSS.

Considering the conducted studies and the definitions, we have improved a web-based system working interactively with physicians. It helps physicians to get the most suitable solution depending on the criteria that associated with each 
other and have multiple structures through the modules in the database, and so it accelerates the diagnosis and treatment process. This system was brought into use for pediatricians after the preparation of infrastructure.

In our study, we preferred pediatric clinics, because these clinics are very busy clinics in the hospitals. Childhood involves a wide range of time from bird up to the age 18 . Children's growth and development changes continuously. The measurements which are made among healthy children depending on gender and age are taken as a basis of comparison all around the world. However, these measurements cannot be taken because of the excess workload of polyclinics, emergency and services, or the measurements obtained in very different ranges of data do not allow for comment. The correct interpretation of these measurements will provide the opportunity to early diagnosis, treatment and monitoring of many diseases.

\section{DECISION SUPPORT SYSTEMS}

Decision Support Systems (DSS) have been defined in many ways in the literature. Lu et al. described DSSs as the information systems supporting the decision-makers by using of data and analysis [8]. On the other hand, CDSSs, as a kind of DSS, are computer programs assisting physicians and other medical officials in taking a decision [1].

The components of a DSS mainly consist of a database, inference engine and user interface as can be seen in Figure 1. Inference engine is named as model base in the literature as well. This component is the section in which decision making, optimization, simulation, estimation and analysis models will take place. It is considered that these models carry the users to the right results [9]. The database, which is another part of the system, includes the information and sentences of rules about to the problem. In this study, the related experiences were added to the database of Web-based PDSS by a specialist in pediatric. On the other hand, the user interface provides interactivity among inference engine, database and users.

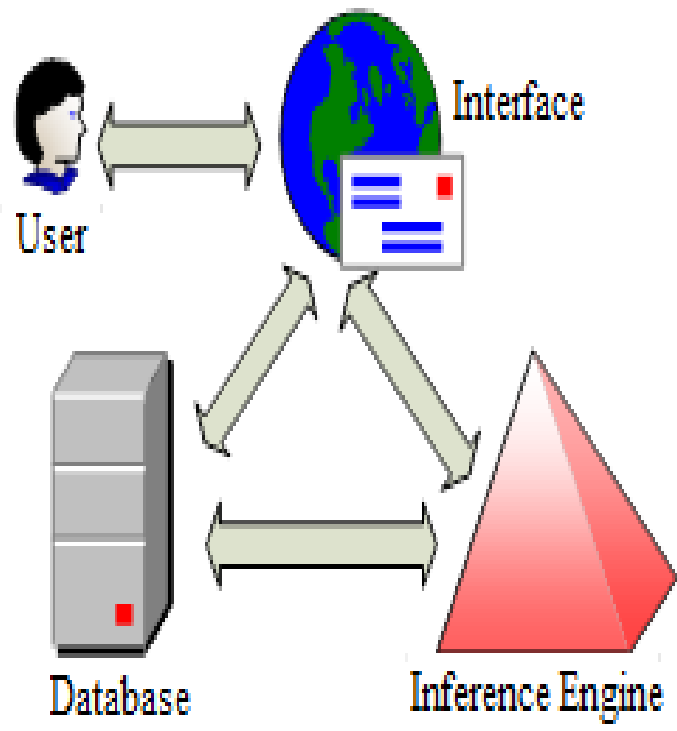

Fig 1: The components of a Decision Support System [9].

DSSs are classified as five types including model (modeldriven DSS), data (data-driven DSS), knowledge (knowledgedriven DSS), group and web-based [8]. Although group and web-based DSSs are similar to each other, there is only a difference between them. If $\mathrm{A}$ work team shares data on a single platform, this is a group DSS. Otherwise, if the members of the group share their thoughts and decisions about to the problem through a network by using their personal computers, this is a web-based DSS. Therefore, although our work seems like only a web-based decision support system, but also it is considered as a group decision support system.

A web-based DSS can be model-driven, data-driven, document-driven, knowledge-driven, communications-driven and hybrid structure including multiple types [9].

\section{RELATIONAL DATABASE MODEL}

Relational database model is used in almost all advanced software and web technologies that require the usage of database. The important points here are design and normalization of the database. There are many advantages of making a good relational database. The main advantages of the management of relational database are the reduction of duplicated data, the improvement of the database control and the ensuring flexibility by reducing the workload. These advantages can change parallel to the qualification of the designed database. There are three kinds of relationship in the relational database; one to one, one to many and many to many relationships.

In this study, we used many to many relational database. According to the many to many relational database, a row in a table is correlated with a lot of rows in the correspondent table and vice versa [10].

\section{IMPLIMENTATION}

\subsection{Database Structure}

In our work, we utilized Java programming language, ZK framework and MySQL database for developing a Web-based PDSS, and used a relational database for correlating diseases with diagnosis and symptoms. The system has been capable of working such as a rule-based system by means of relational database. Data mining methods are performed with IF-THEN rules in the rule-based systems. On the other hand, in our system, an expert person who has an administrator privilege realizes rule definitions by establishing the relationships among Symptom, Laboratory Findings and Diseases by way of the relational database.

In the enhanced Web-based PDSS, an ID value of the symptom which a user chooses is obtained from the database, and is added to SQL statement. The ID values belonging to each chosen symptom and laboratory finding are added to SQL statement according to specific rules. So, a list of diseases is generated in the result of queries made by this SQL statement. In an example, a SQL query expression is as follows.

\section{WHERE diseaseid in (SELECT diseaseid FROM symptomstodiseases WHERE symptomid=340) \\ and diseaseid in (SELECT diseaseid FROM symptomstodiseases WHERE symptomid $=255$ ) \\ and diseaseid in (SELECT diseaseid FROM labparamstodiseases WHERE labparamid=697) \\ group by diseasename}

According to this expression, "11-BETA-HYDROXYLASE DEFICIENCY (CYP11B1)" disease was found depending on the ID values which are belonged to chosen symptoms and laboratory findings. The tables and relations used in our system can be seen in Figure 2 clearly. 


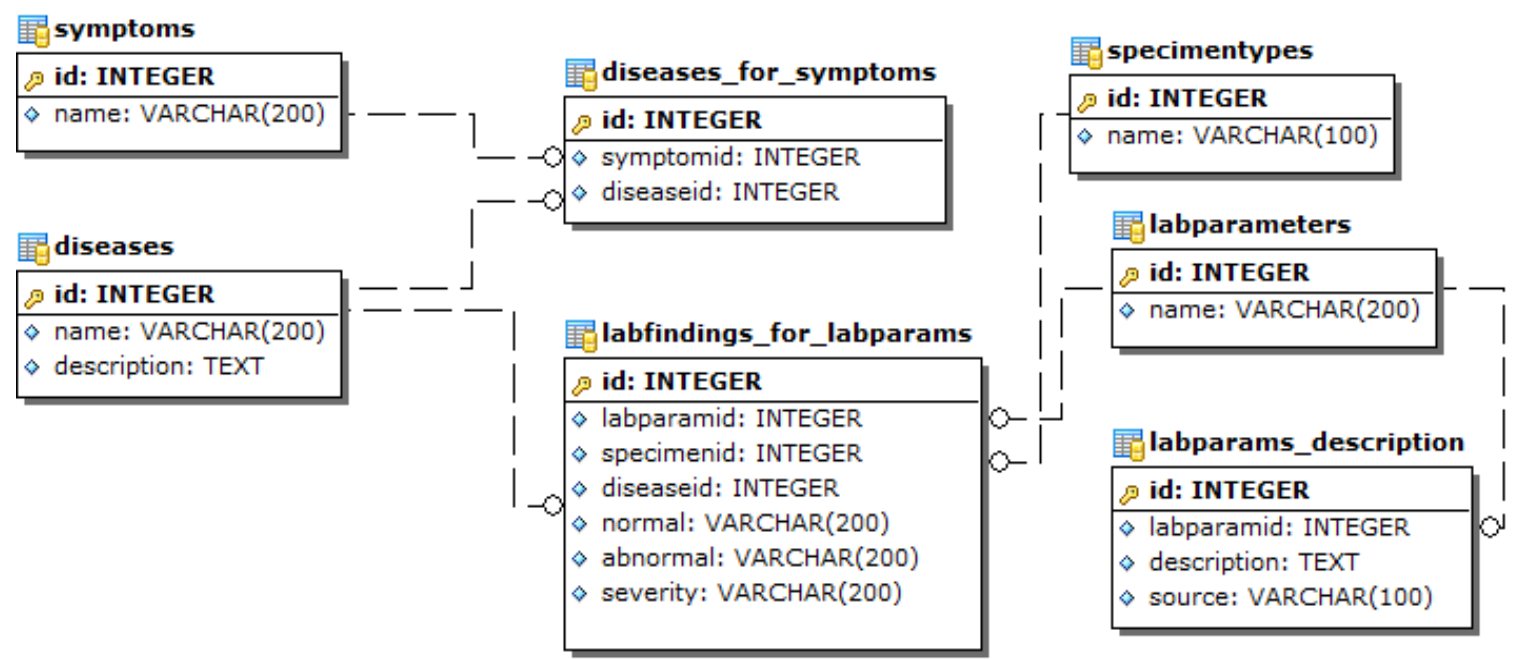

Fig 2: The table relationships in the database.

\subsection{Design and Development}

ASP.NET and Visual Studio 2008 platform with AJAX support were used for developing the Pediatric Decision Support Website. Moreover, we utilized Microsoft Expression Web software at the designing stage of the website.

While we were designing the website at the content determining stage, we investigated that how a specialist decides for diagnosis/treatment. The ways that when making decisions of specialists were been manual for us to determine the structure of the website. Two parameters stand out while physicians decide to diagnosis of any disease. One of these is symptoms, and the other is laboratory findings. The diagnosis and treatment process are realized in the light of these parameters. In developed website, physicians similarly proceed step by step to diagnosis and treatment procedure according to symptoms and laboratory findings obtained from patients.

The user panel was designed user friendly as can be seen in Figure 3. Symptoms are determined by using search area through this panel. Then, possible diseases are listed by selecting laboratory findings about queried symptoms with a multi-choice.
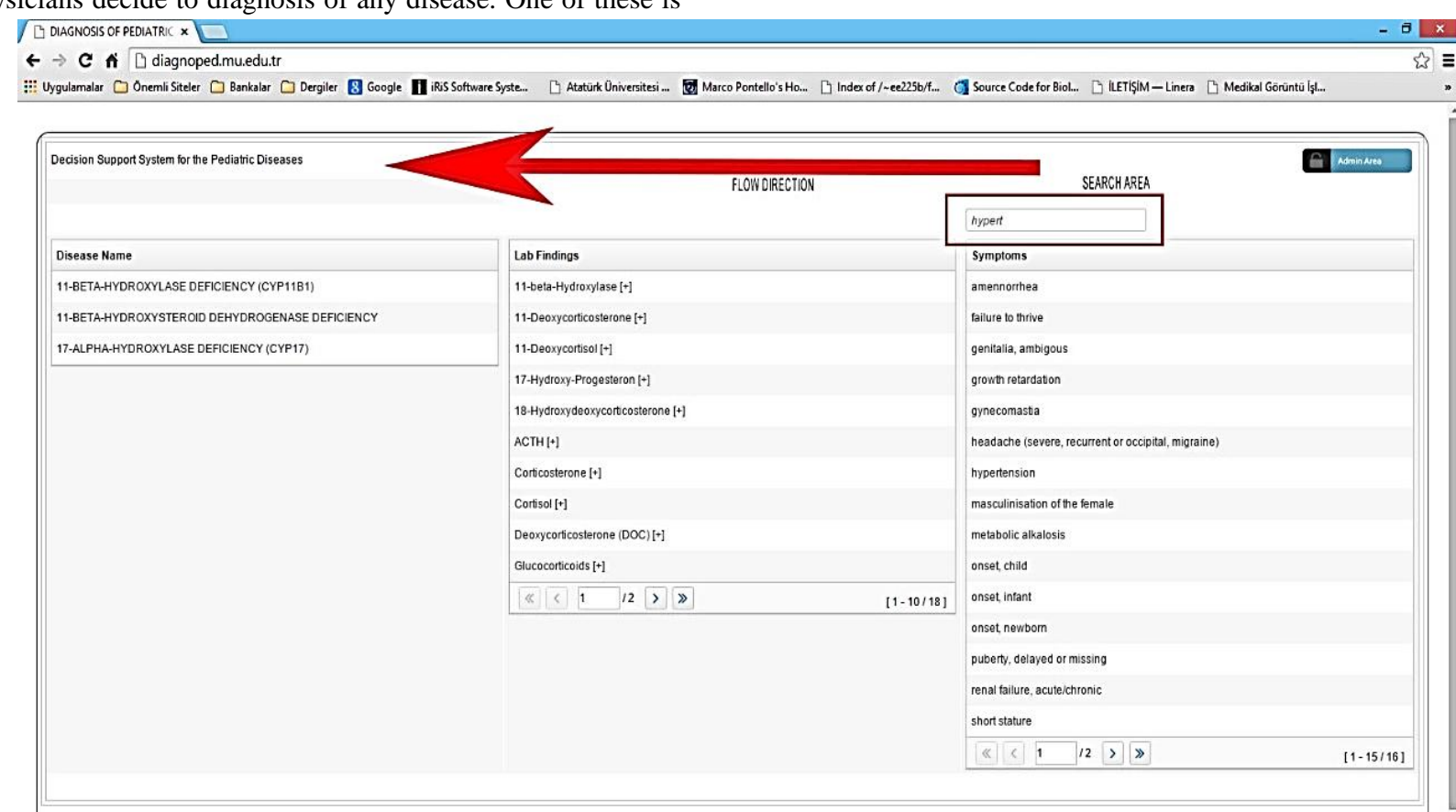

Fig 3: The User Panel of Pediatric DSS Website

The Web-based PDSS was designed to be an extensible structure. Every specialist who has a valid account can record encountered cases and symptoms to the system. The data entry menu used by physicians can be seen in Figure 4. It shows the administration panel, and the operations that can be performed in this panel is as follows;

-DiagnoPed Users: It is used to assign an administrator privileges and to determine the roles in this panel.
-DiagnoPed Definitions: It is used for entering diseases, symptoms, laboratory parameters and specimen types.

-Managing Relations: The data entered from DaignoPed Definitions area are correlated with each other by using menus in this area. These correlations can be associated either from symptoms to diseases or from laboratory findings to diseases. 


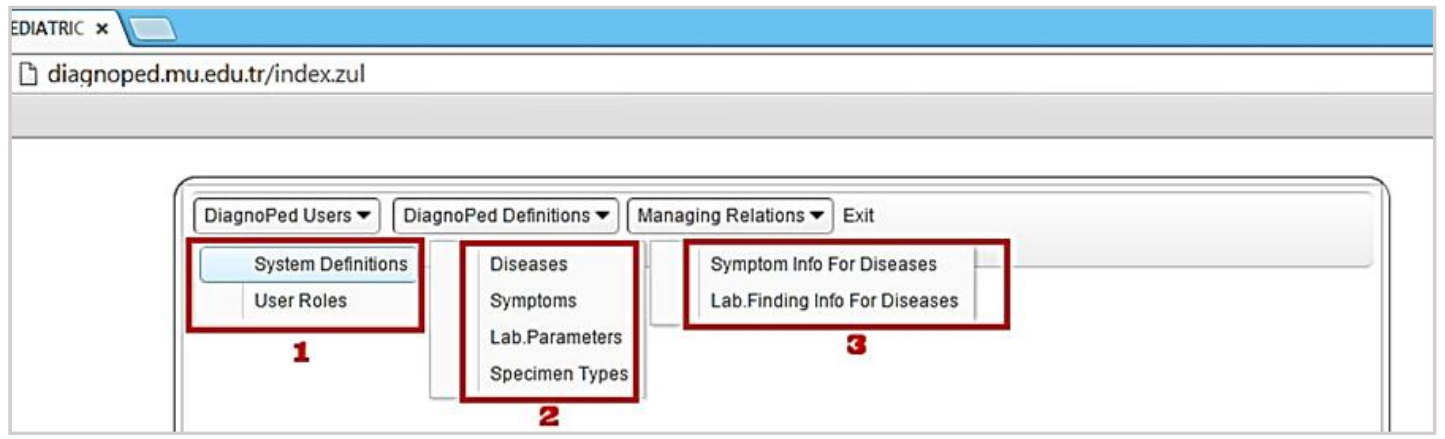

Fig 4: The Administration Panel of Pediatric DSS Website

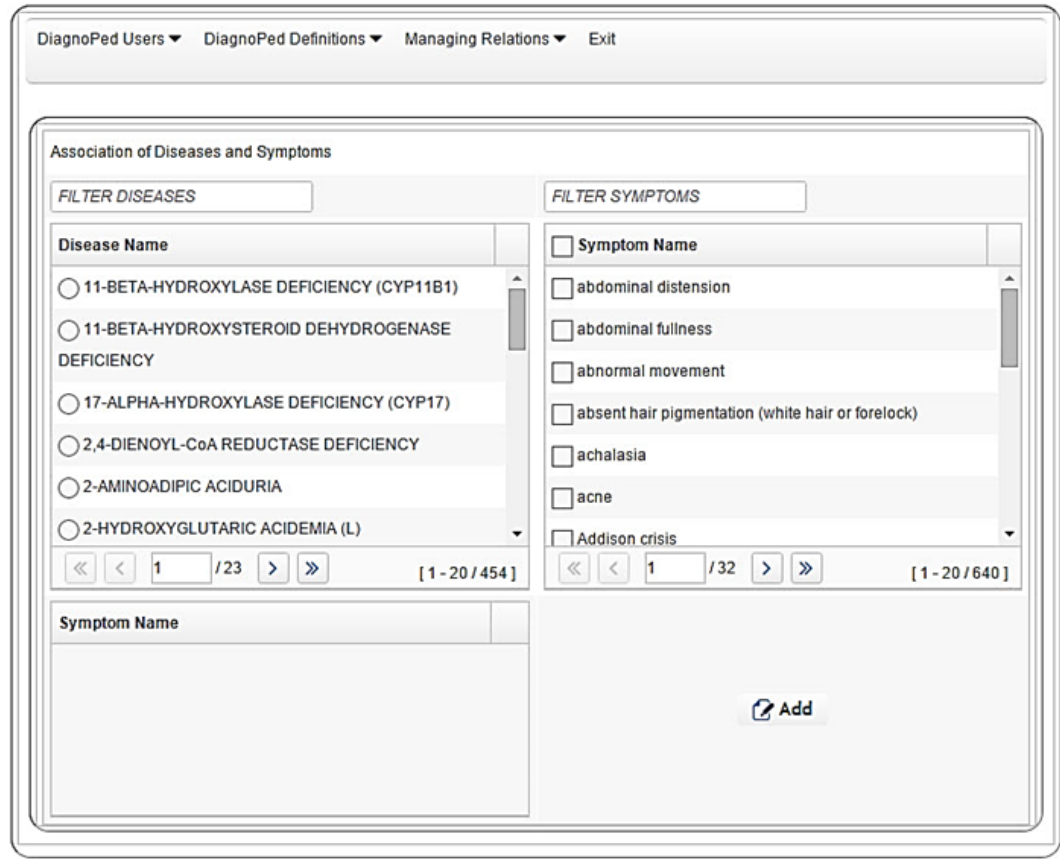

Fig 5: The Association of Diseases and Symptoms Panel

Figure 5. shows the "Associated of Diseases and Symptoms" panel used by a physician who has an administrator account. The relationships are established by using this panel.

\section{EVALUATION OF THE SYSTEM}

The goals of assessment have been specified as to detect comprehended use and functionality of the Web-based PDSS and modify the website according to users' perceptions on its overall design. In this study, System Usability Scale (SUS) was used to provide an overview on the subjective assessment about to the usability of Web-based PDSS. SUS consists of 10 questionnaires [11], and it can be used for evaluating many products including software, hardware, websites, mobile devices and applications.

The physicians used and investigated the Web-based PDSS by themselves in their clinics. Then, the survey was applied to physicians for evaluating our web-based system and for determining the usability of the website such as a decision support system.

\subsection{Participants}

The evaluation questionnaires were completed by 23 physicians. $13(54.2 \%)$ of them are working in pediatric service, and $10(41.7 \%)$ of them are working in an emergency service. Of these physicians, $66.7 \%$ are specialist in pediatrics and $29.2 \%$ were not a specialization. Of the physicians' professional experience, $25 \%$ were between 10 years and up, $33.3 \%$ were between $5-10$ years, $37.5 \%$ were between $0-5$ years.

\subsection{Data Analysis}

Survey items are strongly disagree, disagree, neutral, agree and strongly agree (They varies from 1 to 5 respectively). According to SUS, the survey score can range from 0-100. The height of the scores indicates that the usability of a system is high. The score contributions of each item is summed to calculate the SUS score. These score impacts can change from 0 to 4 . While some items $(1,3,5,7$ and 9) have value of 1 as score impact, the others $(2,4,6,8$ and 10) have value of 5 . The overall value of SU is obtain by multiplexing the sum of these scores by 2.5 [11].

Survey data were inputted and analyzed into the SPSS (Statistical Package for the Social Sciences) 22.0 program. The descriptive statistics (sum, mean, percent, and frequency) and nonparametric tests (Mann-Whitney $U$ and KruskalWallis $\mathrm{H}$ ) were used for analyzing survey data.

\subsubsection{The Usability of Web-based PDSS}

10 questionnaires were applied to physicians for the usability of the Web-based Pediatric DSS. The descriptive statistics of Web-based PDSS with these questionnaires are detailed in Table 1. 
Table 1. Descriptive analysis of 10 questionnaire ratings

\begin{tabular}{|c|c|c|}
\hline Survey items & Mean & sd. \\
\hline $\begin{array}{l}\text { I think that I would like to use this system } \\
\text { frequently }\end{array}$ & 3.86 & 0.91 \\
\hline I found the system unnecessarily complex & 2.08 & 1.04 \\
\hline I thought the system was easy to use & 4.26 & 0.86 \\
\hline $\begin{array}{l}\text { I think that I would need the support of a } \\
\text { technical person to be able to use this } \\
\text { system }\end{array}$ & 2.13 & 1.09 \\
\hline $\begin{array}{l}\text { I found the various functions in this system } \\
\text { were well integrated }\end{array}$ & 4.30 & 0.70 \\
\hline $\begin{array}{l}\text { I thought there was too much inconsistency } \\
\text { in this system }\end{array}$ & 1.65 & 0.64 \\
\hline $\begin{array}{l}\text { I would imagine that most people would } \\
\text { learn to use this system very quickly }\end{array}$ & 4.21 & 0.73 \\
\hline I found the system very cumbersome to use & 2 & 0.73 \\
\hline I felt very confident using the system & 3 & 1.12 \\
\hline $\begin{array}{l}\text { I needed to learn a lot of things before I } \\
\text { could get going with this system }\end{array}$ & 1.91 & 0.84 \\
\hline
\end{tabular}

The score on efficiency (mean=4.30) indicates that physicians felt that they were satisfied with the functionality of the enhanced system as shown in Figure 6. Furthermore, the physicians found that the web pages which have been easy to use contents (mean=4.26), and they thought that they could use the system often (mean=3.86). On the other hand, the system did not achieve a strong score on the scale of user confidence which was measuring to the physicians felt about to the usage of this system confidently (mean=3.0). The usability score of the scale was found as $73.6(0-100)$ according to participation level of the physicians to the expressions in the System Usability Scale.

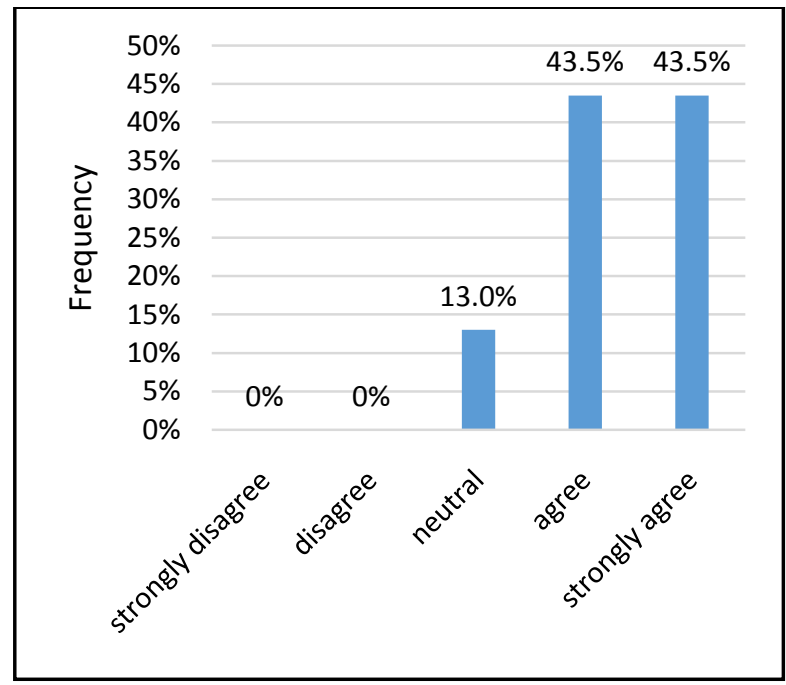

Fig 6: The percent of survey's questionnaires items for Web-based PDSS efficiency

Table 2 shows the results of descriptive analysis with respect to questionnaires' items for the learnability of the system. According to the result of survey questionnaire items, physicians considered that the Web-based PDSS could be learned easily (Agree, 56.5\%).

Table 2. The results of descriptive statistics about to the learnability of the Web-based PDSS

\begin{tabular}{|l|l|l|}
\hline Survey Item Results & Frequency & Percent (\%) \\
\hline Strongly Disagree & 0 & 0 \\
Disagree & 1 & 4.3 \\
Neutral & 1 & 4.3 \\
Agree & 13 & 56.5 \\
Strongly Agree & 8 & 34.8 \\
\hline Total & 23 & 100 \\
\hline
\end{tabular}

5.2.2 The Findings Related to Differences in the Usability

In this section, we analyzed to the differences between the assessments of the physicians about to the usability factors of the system. To determine these differences, Mann-Whitney U and Kruskal-Wallis $\mathrm{H}$ nonparametric test methods were used.

From the Mann-Whitney U test's results of our data, it can be concluded that the total usability of our system according to departments of the physicians was not a statistically difference $(\mathrm{U}=49.5, \mathrm{p}>.05(.32))$. However, when we tested each item of the survey, we saw that there was a meaningful statistical differentiation ( $\mathrm{U}=28.0, \mathrm{p}<.05(.047))$ in the use of the system between the departments of the physicians. As shown in Table 3, the physicians who have not a specialization have more preferred to the use of the system than the specialists.

Table 3. The differences between the specialists and the physicians about to the use of the system

\begin{tabular}{|ll|l|l|l|}
\hline & Specialist & N & $\begin{array}{l}\text { Mean } \\
\text { Rank }\end{array}$ & $\begin{array}{l}\text { Sum of } \\
\text { Ranks }\end{array}$ \\
\hline $\begin{array}{l}\text { I think that I } \\
\text { would like to } \\
\text { use this }\end{array}$ & Yes & 16 & 10.25 & 164.00 \\
$\begin{array}{l}\text { system } \\
\text { frequently }\end{array}$ & 7 & 16.00 & 112.00 \\
\hline
\end{tabular}

The Mann-Whitney U test's results also showed that the physicians in the emergency service were found that the material more usable than the physicians in pediatric service $(\mathrm{U}=68, \mathrm{p}<.05(.042))$.

Kruskal-Wallis $\mathrm{H}$ test showed that there was not a statistically significant difference in seniority to system usability, X2(2) = $2.340, p=0.31$, with a mean rank seniority score of 13.50 for $0-5$ years, 13.56 for 5-10 years and 9.13 for 10 years and up as shown in Table 4.

Table 4. The differences between the physicians according to their seniority.

\begin{tabular}{|ll|l|l|}
\hline \multicolumn{1}{|c|}{ Seniority } & $\boldsymbol{N}$ & Mean Rank \\
\hline Total & 0-5 years & 7 & 13.50 \\
& 5-10 years & 8 & 13.56 \\
10 years and up & 8 & 9.13 \\
Total & 23 & \\
\hline
\end{tabular}




\section{DISCUSSION AND FUTURE SCOPE}

In this study, a Web-based Pediatric Decision Support System is proposed to guide and assist pediatricians about clinical issues. It was constructed using many to many relational database, and the related experiences were added to the database by a specialist in pediatric. In the light of entered symptom and laboratory data, we realized the diagnosis and treatment process of pediatric patients. The usability of the Web-based PDSS was tested with System Usability Scale after the development process. According to test results, the usability score of scale is high, and the system is preferable. Moreover, the physicians pleased to the functionality of Webbased PDSS. However, the results also indicate that our system did not accomplish a strong score on the scale of user confidence which was measuring to the physicians felt about to the usage of this system confidently.

We expected that the application of Web-based PDSS will contribute to service quality in the clinical examination of pediatric patients. Later in the study, we will consider further more pediatric patients in our system to measure the accuracy of our system, and we will analyze decision results.

The importance of DSSs are increasing day by day, and they are strengthening the position in the field of technology. The significance of these systems depends on the accuracy of the system and the decision-making ability. For this reason, in future, we will explore intelligent decision-making systems based on expert systems and data mining as alternative methods. An expert system emulates the decision-making capability of a human expert. On the other hand, data mining method is an extraction process of the patterns in huge data sets. It is obvious that these methods have the potential to improve the performance of our system.

\section{REFERENCES}

[1] Özata, M. and Aslan, Ş., 2004. Klinik Karar Destek Sistemleri ve Örnek Uygulamalar. The Medical Journal of Kocatepe, Vol 5, No 2, 11-17.

[2] Musen, A. M., Shadar, Y. and Shortliffe, E. H. 2006. Clinical Decision-Support Systems, Biomedical
Informatics Computer Applications in Health Care and Biomedicine, New York, Springer, 698-736.

[3] Uzoka, F. M. E, Osuji, J. and Obot, O. 2011. Clinical decision support system (DSS) in the diagnosis of malaria: A case comparison of two soft computing methodologies. Expert Systems with Applications, Vol $38,1537-1553$.

[4] Pala, T., 2013. Tibbi Karar Destek Sisteminin Veri Madenciliği Yöntemleriyle Gerçekleştirilmesi, Master Thesis. Marmara University, İstanbul.

[5] Wicht, A., Wetter, T. and Klein, U. 2013. A web-based system for clinical decision support and knowledge maintenance for deterioration monitoring of hematooncological patients. Computer Methods and Programs in Biomedicine, 26-32.

[6] Özel, D., Bilge, U., Zayim, N., Cengiz, M., Özbek, F. and Saka, O. 2010. Web Tabanlı Yoğun Bakım Karar Destek Sistemi, VII. National Congress of Medical Informatics.

[7] Basilakis, J., Lovell, N. H., Redmond, S. J. and Celler, B. G., 2010. Design of a Decision-Support Architecture for Management of Remotely Monitored Patients. IEEE Transactions on Information Technology in Biomedicine, Vol 14, No. 5, 1216-1226.

[8] Lu, J., Zhang, G., Ruan, D. and Wu F., 2007. MultiObjective Group Decision Making: Methods Software and Applications with Fuzzy Set Technigues, Singapure: Imperial Collage Press.

[9] Çebi, S., 2010. Aksiyomlarla Tasarım Esaslı Bulanık Karar Destek Sistemi Geliştirme ve Bir Uygulama. Doctoral Thesis. İstanbul Technical University, İstanbul.

[10] Nizam, A., 2011. Veritabanı Tasarımı: İlişkisel Veri Modeli ve Uygulamaları. İstanbul: Papatya Yayıncılık.

[11] Brooke, J., 2014. SUS - A quick and dirty usability scale, [Online]. Available: http://cui.unige.ch/isi/icle-wiki/ _media/ipm:test-suschapt.pdf.. 